\title{
Effect of Components in Chinese Sauerkraut Powder on Quality of Chinese Cantonese Sausage
}

\author{
Heng Guo ${ }^{1, a}$, Xiaona $\mathrm{Qi}^{2, b}$, and Anjun Liu ${ }^{*}$, , c \\ ${ }^{1,2,3}$ Key Laboratory of Food Nutrition and Safety, Ministry of Education, College of Food Engineering and \\ Biotechnology, Tianjin University of Science and Technology, Tianjin 300457, China \\ aghguoheng@qq.com, ’291993184@qq.com, laj@tust.edu.cn
}

Keywords: Chinese Cantonese sausage; sauerkraut powder; texture; physicochemical property

\begin{abstract}
With the desire for improving the product quality and a balanced diet, a new kind of Chinese Cantonese sausage with Chinese sauerkraut powder which was rich in dietary fiber was manufactured and then studied. The texture profile and physicochemical property including moisture content, fat content, sugar content, $\mathrm{pH}$ value and color were evaluated. The effects of sauerkraut powder on moisture and fat content were not significant, but it led to a lower sugar content and $\mathrm{pH}$ value in Cantonese sausage. $\mathrm{L}^{*}, \mathrm{a}^{*}$ and $\mathrm{b}^{*}$ showed a downward trend with the increasing addition of sauerkraut powder. Texture profile analysis (TPA) showed a significantly decline in hardness, gumminess and chewiness and a rise in cohesiveness. The sensory evaluation showed that when the content of Chinese sauerkraut powder reached $1.0 \%$, the sauerkraut powder had a positive impact on the sausage and it could be accepted by the most of the panelists.
\end{abstract}

\section{Introduction}

Chinese Cantonese sausage mostly produced in Guangdong province is one of the traditional Chinese semi-dry sausages with thousands of years. Sausages are made by mixing with a few spices in the ground meat, which have been a worldwide meat production with a vast and booming market due to rich nutrition, good taste and convenient characteristic ${ }^{[1]}$. However, the high content of cholesterol, saturated fatty acid and lack of dietary fiber in the Cantonese sausage ${ }^{[2]}$, therefore, it is very urgent to improve the quality and nutrition of Cantonese sausage.

Sauerkraut is a kind of vegetable product that is fermented by pickled cabbage or green vegetables, which has a long history of edible consumption in China. Sauerkraut can preserve the nutrients in the original vegetables to the maximum, and also contains rich vitamin C, amino acid, organic acid, dietary fiber and other functional ingredients. Besides, the production of lactic acid in the process of fermentation also provides unique flavor of sauerkraut ${ }^{[3]}$. Moreover, lactic acid can inhibit the growth of spoilage bacteria in the large intestine and maintain the normal physiological function in the gastrointestinal tract ${ }^{[4]}$.

With the strengthening awareness of healthy diet, diet balance has become people's goal. In addition, the conscious intake of cellulose is also gradually increased in daily life. However, there are few research on adding Chinese sauerkraut into Cantonese sausage to increase the unique flavor and improve the contents of fiber. In this study, we made this kind of novel sauerkraut sausage and analyzed the effects of sauerkraut powder on its quality.

\section{Materials and methods}

\subsection{Raw materials}

Pork hind leg muscle were brought from the TESCO supermarket. The Chinese sauerkraut (Northeast sauerkraut, Tianjin, China) was dried with a drying box (GZX-9070MBE, Shanghai, China). The dried sauerkraut was crushed by a disintegrator (FW100, Tianjin, China), which was then sifted through 60 mesh to make sauerkraut powder. 


\subsection{Sample preparation}

Lean meat and lard were minced separately using a meat chopper (SYP-MM22, Guangdong, China) with a evenly distributed sieve plate of $5 \mathrm{~mm}$-diameter holes. The sodium nitrite $(0.01 \%)$ was added in lean meat and them were stored at $4{ }^{\circ} \mathrm{C}$ for $6 \mathrm{~h}$. The same kinds of spices and different proportion of Chinese sauerkraut powder were added into each group and stirred to mix (the amount and proportion of spices and Chinese sauerkraut powder were exhibited in Table 1). Sample in each group was chopped for $10 \mathrm{~s}$ and made them become meat batter with a food processor (JYL-D020, Jiangsu, China), then stored at $4{ }^{\circ} \mathrm{C}$ for $12 \mathrm{~h}$. Subsequently, the mixture was filled in artificial collagen protein casings with No.26 (the diameter of the casing 26mm) (Jiangsu Long Hui Livestock Products Co., Ltd., Jiangsu, China) using a stuffer and then the Chinese Cantonese sausage was tied at every $10 \mathrm{~cm}$. After this process, Cantonese sausages were marked and dried in a drying box (GZX-9070MBE, Shanghai, China) at $52{ }^{\circ} \mathrm{C}$ for $48 \mathrm{~h}$. After chilling-down at room temperature, samples were vacuumized using vacuum package machine (TC-5000, Shanghai, China) and stored at $4{ }^{\circ} \mathrm{C}$. Finally, sample in each group was randomly selected and $\mathrm{pH}$ value, chromatic aberration, moisture content, fat content, sugar content, texture profiled analysis and sensory evaluation were detected. All experiments were performed at least three times.

Table 1 Cantonese sausage formulation with sauerkraut powder

\begin{tabular}{llllll}
\hline Group ${ }^{\mathrm{A}}(\mathrm{w} / \mathrm{w})$ & $\mathrm{S} 0.0 \%{ }^{\mathrm{B}}$ & $\mathrm{S} 0.5 \%{ }^{\mathrm{B}}$ & $\mathrm{S} 1.0 \%{ }^{\mathrm{B}}$ & $\mathrm{S} 1.5 \%{ }^{\mathrm{B}}$ & $\mathrm{S} 2.0 \%{ }^{\mathrm{B}}$ \\
\hline Lean meat $(\mathrm{g})$ & 160 & 160 & 160 & 160 & 160 \\
Lard $(\mathrm{g})$ & 40 & 40 & 40 & 40 & 40 \\
Sodium nitrite & 0.01 & 0.01 & 0.01 & 0.01 & 0.01 \\
Sugar & 8 & 8 & 8 & 8 & 8 \\
liquor & 8 & 8 & 8 & 8 & 8 \\
salt & 1.5 & 1.5 & 1.5 & 1.5 & 1.5 \\
Chicken essence & 0.3 & 0.3 & 0.3 & 0.3 & 0.3 \\
composite & 0.2 & 0.2 & 0.2 & 0.2 & 0.2 \\
phosphate & 0.05 & 0.05 & 0.05 & 0.05 & 0.05 \\
Vitamin C & 0.0 & 0.5 & 1.0 & 1.5 & 2.0 \\
sauerkraut powder & 0.0 & &
\end{tabular}

${ }^{\mathrm{A}}$ Based on the total weight of the ground meat. ${ }^{\mathrm{B}} \mathrm{S} 0.0 \%=0.0 \%$ Chinese sauerkraut powder, $\mathrm{S} 0.5 \%=0.5 \%$ Chinese sauerkraut powder, S1.0\%=1.0\% Chinese sauerkraut powder, S1.5\%=1.5\% Chinese sauerkraut powder, S2.0\%=2.0\% Chinese sauerkraut powder.

\subsection{The determination of physico-chemical properties}

Chemical compositions (moisture, fat, and sugar) of Cantonese sausages samples was measured according to Chinese National Standard GB/T 9695.15-2008, GB/T 9695.7-2008, and GB/T 9695.31-2008, respectively. The moisture content was detected using an oven (DZF-6020, Shanghai, China). The samples were dried at $105 \pm 2{ }^{\circ} \mathrm{C}$ until constant weight; Fat content was determined by the Soxhlet method with a petroleum ether extraction system (SZC-101, Huana, China), and the extracting organic solvent was petroleum ether whose boiling range is $30-60{ }^{\circ} \mathrm{C}$; Total sugar was quantified by the phenol-sulfuric acid method with a BioTek microplate reader (Genesys 10S UV-Vis, Shanghai, China) at the wavelength of $470 \mathrm{~nm}$. The determination of $\mathrm{pH}$ values was carried out according to the Chinese National Standard GB/T 5009.237-2016. $10 \mathrm{~g}$ of each ground sample was mixed with $100 \mathrm{ml}$ of distilled water and homogenized using a homogenizer (IKA T25, Shanghai, China), and then they were measured using a table pH meter (Five Easy Plus, Changzhou, China).

The determination of instrumental color values of each sample was using a portable Spectrocolorimeter (CM-700 d, Osaka, Japan). The CIELAB space was used to measure the value of color with a presentation of $\mathrm{L}^{*}$ (Lightness), $\mathrm{a}^{*}$ (redness) and $\mathrm{b}^{*}$ (yellowness). Each sample was measured 3 times. 


\subsection{The determination of texture}

The texture profile analysis (TPA) of Cantonese sausages was measured according to the previous method ${ }^{[5]}$. The TPA in each group sample was detected by Stable Micro Systems texture analyses (TA. XT Plus, Stable Mico System, UK). Briefly, the samples were cut into cylindrical shape with a height of $1 \mathrm{~cm}$ and a diameter of $1 \mathrm{~cm}$, and the test was performed with a speed of 2 $\mathrm{mm} / \mathrm{s}$ before determination, $1 \mathrm{~mm} / \mathrm{s}$ between and after determination. Following five indicators were measured: hardness, springiness, cohesiveness, gumminess and chewiness.

\subsection{Sensory evaluation}

The sensory evaluation was carried out in a standard sensory evaluation room. The sensory evaluation panel contained 20 panelists who are certainly sensitive to the quality change of Cantonese sausage and have been professional trained according to GB/T22210-2008. After sausage in each group was steamed at $100{ }^{\circ} \mathrm{C}$ for $5 \mathrm{~min}$, they were sliced into pieces about $2 \mathrm{~mm}$ and placed 3 pieces of each sample into a white porcelain plate individually. The five samples were randomly grouped and randomly assigned to every panelist. In the end of evaluation, the score chart about aroma, color, texture and taste of sausage was achieved. A 9-point preference scale was used to evaluate these parameters: from 0 (dislike extremely) to 9 (like extremely).

\subsection{Statistical analysis}

All the experiments were repeated three times $(n=3)$ in same condition and samples were randomly selected used testing. Data handling was using SPSS 17.0 (Chicago, USA) and significant difference analysis was using One-Way ANOVA and the Duncan's test. And the results were presented as mean value \pm standard deviation of triplicate determinations. There was a significant difference between the mean values of each group when $P<0.05$.

\section{Results and discussion}

Table 2 Effect of sauerkraut powder on physico-chemical properties of Cantonese sausage

\begin{tabular}{llllll}
\hline Sauerkraut & $0 \%$ & $0.5 \%$ & $1 \%$ & $1.5 \%$ & $2.0 \%$ \\
\hline Moisture (\%) & $24.35 \pm 0.31^{\mathrm{ab}}$ & $24.46 \pm 0.34^{\mathrm{ab}}$ & $25.11 \pm 0.25^{\mathrm{b}}$ & $24.28 \pm 0.41^{\mathrm{a}}$ & $24.51 \pm 0.60^{\mathrm{ab}}$ \\
Fat (\%) & $24.78 \pm 0.75^{\mathrm{a}}$ & $25.33 \pm 1.56^{\mathrm{a}}$ & $25.76 \pm 1.03^{\mathrm{a}}$ & $25.51 \pm 0.60^{\mathrm{a}}$ & $24.80 \pm 0.26^{\mathrm{a}}$ \\
PH & $6.43 \pm 0.01^{\mathrm{d}}$ & $6.30 \pm 0.02^{\mathrm{c}}$ & $6.11 \pm 0.03^{\mathrm{b}}$ & $6.02 \pm 0.05^{\mathrm{b}}$ & $5.82 \pm 0.03^{\mathrm{a}}$ \\
Sugar (\%) & $3.93 \pm 0.02^{\mathrm{a}}$ & $3.69 \pm 0.03^{\mathrm{b}}$ & $3.25 \pm 0.01^{\mathrm{c}}$ & $3.01 \pm 0.03^{\mathrm{d}}$ & $2.79 \pm 0.01^{\mathrm{e}}$ \\
$\mathrm{L}^{*}$ & $48.77 \pm 1.29^{\mathrm{e}}$ & $46.93 \pm 2.31^{\mathrm{d}}$ & $45.49 \pm 0.45^{\mathrm{c}}$ & $44.26 \pm 1.40^{\mathrm{b}}$ & $42.67 \pm 1.09^{\mathrm{a}}$ \\
$\mathrm{a}^{*}$ & $17.42 \pm 0.52^{\mathrm{a}}$ & $15.50 \pm 0.48^{\mathrm{b}}$ & $12.62 \pm 0.37^{\mathrm{c}}$ & $10.90 \pm 0.12^{\mathrm{d}}$ & $9.82 \pm 0.23^{\mathrm{e}}$ \\
$\mathrm{b}^{*}$ & $16.35 \pm 0.26^{\mathrm{d}}$ & $15.01 \pm 0.48^{\mathrm{c}}$ & $14.42 \pm 0.39^{\mathrm{c}}$ & $13.55 \pm 0.47^{\mathrm{b}}$ & $12.63 \pm 0.35^{\mathrm{a}}$ \\
\hline
\end{tabular}

Data are express as means \pm standard deviation. Averages within the same line followed by the same letters did not show any significant difference $(P>0.05)$ by Duncan's test.

\subsection{Analysis of physico-chemical properties}

The effects of sauerkraut powder on chemical composition of Cantonese sausage were showed in Table 2. There were no significantly differences for moisture and fat in Cantonese sausage between all groups $(P>0.05)$, which may be related to the low moisture and fat content in the sauerkraut powder. However, with the increase of sauerkraut powder concentration, the $\mathrm{pH}$ values of all samples decreased $(P<0.05)$ significantly (Table 2$)$. The result was in agreement with the research which indicated $\mathrm{pH}$ value of Chinese sauerkraut was around 3.25 at the end of fermentation and thus led to low PH in Cantonese sausage ${ }^{[6]}$.

The result (Table 2) showed that sugar content of all samples strikingly decreased $(P<0.05)$ with the increase of sauerkraut powder concentration. In the heating process, the high temperature $\left(52^{\circ} \mathrm{C}\right)$ accelerated the degradation of sugar and the formation of the glucose and laevulose. Then the glucose and laevulose contained carbonyl group ${ }^{[7]}$ reacted with the compounds (amino acid and protein) contained amino to generate new compounds, which led to the decrease of sugar content. In 
addition, the low of $\mathrm{pH}$ may benefit the degradation of sugar and promoted proteolysis, which could increase the amount of carbonyl and amino.

The Table 2 showed the effect of sauerkraut powder on the color of Cantonese sausage. Along with the increasing addition of sauerkraut powder, the color of sausage became darker and the lightness significantly decreased $(P<0.05)$. The values of $\mathrm{a}^{*}$ and $\mathrm{b}^{*}$ of all samples decreased $(P<$ 0.05 ) in pace with the increase of the sauerkraut powder. The carbonyl-amine reaction may account for the darker color of the sausage with the addition of sauerkraut powder. The degradation products were used in Carbonyl-amine reaction to produce some brown or black macromolecular substances which played negative roles in $\mathrm{L}^{*}$ of sausage production. And the values of $\mathrm{a}^{*}$ and $\mathrm{b}^{*}$ may have a relationship with the sauerkraut powder for its own color of yellow and a little gloomy. These results tended to agree with the report of Fatimah et al. ${ }^{[8]}$ who added oat bran to surimi. They found that the $b^{*}$ increased, which could be contributed to the carotenoid pigments present in oat bran.

Table 3 Effect of sauerkraut powder on texture properties of Cantonese sausage

\begin{tabular}{llllll}
\hline Sauerkraut & $0 \%$ & $0.5 \%$ & $1.0 \%$ & $1.5 \%$ & $2.0 \%$ \\
\hline Hardness (N) & $43.41 \pm 1.27^{\mathrm{c}}$ & $32.26 \pm 0.95^{\mathrm{b}}$ & $30.82 \pm 0.18^{\mathrm{a}}$ & $30.73 \pm 0.45^{\mathrm{a}}$ & $30.60 \pm 0.54^{\mathrm{a}}$ \\
Springiness & $0.85 \pm 0.03^{\mathrm{a}}$ & $0.83 \pm 0.01^{\mathrm{a}}$ & $0.85 \pm 0.01^{\mathrm{a}}$ & $0.83 \pm 0.02^{\mathrm{a}}$ & $0.84 \pm 0.01^{\mathrm{a}}$ \\
Cohesiveness & $0.66 \pm 0.01^{\mathrm{a}}$ & $0.71 \pm 0.01^{\mathrm{b}}$ & $0.74 \pm 0.01^{\mathrm{c}}$ & $0.74 \pm 0.02^{\mathrm{c}}$ & $0.76 \pm 0.01^{\mathrm{c}}$ \\
Gumminess & $28.65 \pm 1.27^{\mathrm{b}}$ & $22.91 \pm 1.00^{\mathrm{a}}$ & $22.80 \pm 0.24^{\mathrm{a}}$ & $22.73 \pm 0.43^{\mathrm{a}}$ & $23.25 \pm 0.45^{\mathrm{a}}$ \\
Chewiness (N) $^{2}$ & $24.32 \pm 0.23^{\mathrm{a}}$ & $19.01 \pm 1.19^{\mathrm{b}}$ & $19.45 \pm 0.22^{\mathrm{b}}$ & $19.01 \pm 0.15^{\mathrm{b}}$ & $19.52 \pm 0.74^{\mathrm{b}}$ \\
\hline
\end{tabular}

Data are express as means \pm standard deviation. Averages within the same line followed by the same letters did not show any significant difference $(P>0.05)$ by Duncan's test.

\subsection{Analysis of texture properties}

As Table 3 showed, the five texture parameters (hardness, springiness, cohesiveness, gumminess and chewiness) of sausage were tested. The springiness showed there were no obvious differences $(P>0.05)$ in all the samples. Compared with control group, the addition of sauerkraut powder had an evidently positive effect $(P<0.05)$ to soften the texture of sausage production. However, there was no significantly changes $(P>0.05)$ from $1.0 \%$ group to $2.0 \%$ group, which might be due to the proteolysis and the change of the amount of soluble protein ${ }^{[9]}$. The decrease of $\mathrm{pH}$ value gradually approach to isoelectric point and promote the proteolysis to some extent, which may contribute to the decline of hardness ${ }^{[10]}$. In contrast, the down-regulation of hardness was not significant from $1.0 \%$ group to $2.0 \%$ group, which might be associated to the degree of proteolysis. When the addition of sauerkraut powder reached $1.0 \%$, the proteolysis almost attained to the highest level. Therefore, with the increasing concentration of sauerkraut powder, hardness value significantly declined due to the proteolysis, which was consistent with the result that proteolysis played a negative role on hardness $^{[11]}$. Table 3 showed the result of cohesiveness, gumminess and chewiness, there was a relatively significance $(P<0.05)$ between the groups in the presence or absence sauerkraut powder.

Table 4 sensory analysis of Cantonese sausage

\begin{tabular}{llllll}
\hline Sauerkraut & $0 \%$ & $0.50 \%$ & $1.00 \%$ & $1.5 \%$ & $2.0 \%$ \\
\hline Color & $8.37 \pm 0.19^{\mathrm{e}}$ & $7.84 \pm 0.14^{\mathrm{d}}$ & $7.47 \pm 0.18^{\mathrm{c}}$ & $7.02 \pm 0.05^{\mathrm{b}}$ & $6.46 \pm 0.20^{\mathrm{a}}$ \\
Aroma & $7.41 \pm 0.14^{\mathrm{a}}$ & $7.77 \pm 0.08^{\mathrm{b}}$ & $8.35 \pm 0.21^{\mathrm{d}}$ & $8.05 \pm 0.08^{\mathrm{c}}$ & $7.35 \pm 0.06^{\mathrm{a}}$ \\
Taste & $7.44 \pm 0.19^{\mathrm{a}}$ & $8.06 \pm 0.10^{\mathrm{b}}$ & $8.71 \pm 0.16^{\mathrm{c}}$ & $8.17 \pm 0.17^{\mathrm{b}}$ & $7.23 \pm 0.20^{\mathrm{a}}$ \\
Texture & $7.46 \pm 0.10^{\mathrm{b}}$ & $8.26 \pm 0.08^{\mathrm{d}}$ & $8.56 \pm 0.12^{\mathrm{e}}$ & $7.86 \pm 0.11^{\mathrm{c}}$ & $7.13 \pm 0.06^{\mathrm{a}}$ \\
Overall acceptability & $7.27 \pm 0.14^{\mathrm{a}}$ & $7.88 \pm 0.10^{\mathrm{b}}$ & $8.76 \pm 0.10^{\mathrm{c}}$ & $7.96 \pm 0.06^{\mathrm{b}}$ & $7.17 \pm 0.15^{\mathrm{a}}$ \\
\hline
\end{tabular}

Data are express as means \pm standard deviation. Averages within the same line followed by the same letters did not show any significant difference $(P>0.05)$ by Duncan's test.

\subsection{Sensory analysis}

Sensory analysis of Cantonese sausage with different sauerkraut powder concentration was showed in Table 4. The concentration of sauerkraut powder had a great effect on the sensory evaluation. With the increase of sauerkraut powder concentration, the color values of all samples 
decreased $(P<0.05)$ significantly, which was in accordance with the result of the color properties. The overall evaluation was the best when the sauerkraut powder content attained to $1.0 \%$.

\section{Conclusions}

In this study, we investigated the effect of sauerkraut powder on the quality of Cantonese sausage. The addition of sauerkraut powder led to the decrease of $\mathrm{pH}$ value, total sugar content and $\mathrm{L}^{*}$ value in sausage and a tender texture, especially a lower hardness. However, there were no significantly differences for moisture and fat. As our expectation, though the change of color was slightly undesirable, the taste and quality of Cantonese sausage can be the accepted by people when the sauerkraut powder content was $1.0 \%$.

\section{Acknowledgments}

This work was supported by the Ministry of Agriculture of China (No. 201303082-3).

\section{References}

[1] Feng, T., et al., Physicochemical properties and sensory evaluation of Mesona Blumes gum/rice starch mixed gels as fat-substitutes in Chinese Cantonese-style sausage. Food Research International, 50, 1 (2013): p. 85-93

[2] Zhao, M., Study on the Control of Lipolysis and Oxidation in Chinese Cantonese Sausage. Food \& Fermentation Industries, 33, 8 (2007): p. 10-13

[3] Gao, D., et al., Antioxidative and hypolipidemic effects of lactic acid bacteria from pickled Chinese cabbage. 5, 8 (2011): p. 1439-1446

[4] Sun, Q.S., et al., Isolation and identification of the preferably selected lactic acid bacteria from marketed pickled cabbage. Journal of Engineering of Heilongjiang University (2013)

[5] Laranjo, M., et al., Effects of genotype, salt content and calibre on quality of traditional dry-fermented sausages. Food Control, 56, 3 (2015): p. 119-127

[6] Xiong, T., et al., Effects of salt concentration on Chinese sauerkraut fermentation. LWT - Food Science and Technology, 69 (2016): p. 169-174

[7] Peng-Li, X.U., et al., Quality Evaluation and Control of Cantonese Sausage. Modern Food Science \& Technology (2008)

[8] Alakhrash, F., U. Anyanwu and R. Tahergorabi, Physicochemical properties of Alaska pollock (Theragra chalcograma) surimi gels with oat bran. LWT - Food Science and Technology, 66 (2016): p. 41-47

[9] Benito, M.J., et al., Effect of the fungal extracellular protease EPg222 on texture of whole pieces of pork loin. Meat Science, 65, 2 (2003): p. 877-884

[10] Xi, F., et al., Effects of adding red wine on the physicochemical properties and sensory characteristics of uncured frankfurter-type sausage. Meat Science, 121 (2016): p. 285-291

[11] Cilla, I., et al., Factors affecting acceptability of dry-cured ham throughout extended maturation under “bodega” conditions. Meat Science, 69, 4 (2005): p. 789-95 